口

$\supset$

$\vdash$

LEARNING FROM INPUT-OUTPUT MIXES IN DEA: A PROPORTIONAL MEASURE FOR SLACKBASED EFFICIENT PROJECTIONS

by

Laurens CHERCHYE

TOM VAN PUYENBROECK

$\llbracket$

O

Public Economics

Center for Economic Studies

Discussion Paper Series DPS $\mathbf{9 8 . 1 3}$

$\Sigma$

$\supset$

$\simeq$ 


\title{
Learning from Input-Output Mixes in DEA : A Proportional Measure for Slack-Based Efficient Projections
}

\author{
Laurens CHERCHYE* and Tom VAN PUYENBROECK \\ Centrum voor Economische Studiën \\ KU Leuven \\ Naamsestraat 69 \\ B-3000 Leuven, Belgium \\ February 1998
}

\begin{abstract}
Several Data Envelopment Analysis (DEA) models use a radial distance measure that is based on the Debreu-Farrell notion of (in)efficiency. While this measure has an attractive interpretation, its use may be problematic if slacks or zeros in the data are present. The additive DEA model can perfectly deal with these problems, but the meaning of its associated scores is less intuitive than the one attached to the radial measures. We introduce an alternative efficiency measure, based on the results of the additive model, that can be decomposed in a Debreu-Farrell component and a factor that captures differences in input-output mixes w.r.t. those of the best practice reference observation. On an aggregate level, this second component can be considered as an indicator of the dispersion between radial efficiency measurement and results based on the Pareto-Koopmans efficiency notion. On the individual level, the measure allows to regard relative inefficiency as resulting from (i) a divergence of implicit cost price vectors, and (ii) a cost level that is too high, even after adjustment for the implicit cost prices.
\end{abstract}

Keywords: Technical efficiency, additive DEA model, implicit prices

\footnotetext{
${ }^{*}$ Corresponding author. E-mail: Laurens.Cherchye@econ.kuleuven.ać.be
} 


\section{Introduction}

Data Envelopment Analysis (DEA) as an efficiency measurement tool essentially starts from observed data, usually in the context of production, to (i) create a best practice envelope by means of mathematical programming techniques, and (ii) use this reference frontier and a distance concept to compute efficiency measures for all observations. While several DEA-models exist, many of them have in common the use of a relative radial distance measure to be employed in the second of these above steps. Indeed, the two benchmark DEA models of Charnes, Cooper and Rhodes (CCR; 1978,1979) and Banker, Charnes and Cooper (BCC; 1984) aimed to put into practice the notion of efficiency as expressed in the earlier work of Debreu (1951) and Farrell (1957). In an environment where multiple inputs are used to produce multiple outputs, the Debreu-Farrell input measure is computed as one minus the maximum equiproportionate reduction in all inputs which still allows for production of the given amount of output, while the Debreu-Farrell output measure is also defined with reference to the maximum feasible equiproportionate output expansion.

Next to this 'historical' explanation for their popularity, these measures have some attractive properties both for the practitioner who needs to communicate DEA results, and for the scholar interested in the relationship between DEA and the microeconomic theory of production. The former can summarize multiple dimensions in one scalar, and express the (in)efficiency 'score' of any observed productive unit as a degree. The latter may well appreciate the close link between the Debreu-Farrell measure and Shepard's distance function, and the related fact that - even if prices are not observed - the measures have a straightforward cost interpretation. Specifically, they can be written as the ratio of minimal to actual costs (input orientation) or actual to maximal revenues (output orientation), independently of the price vector which is used [see Russell (1985)].

Next to the Debreu-Farrell efficiency notion, there exists another widely used concept introduced by Koopmans (1951), which is commonly referred to as Pareto-Koopmans efficiency. In this case a decision making unit (DMU) is said to be technically efficient if an increase in any output or a decrease in any input requires a decrease in at least one other output or an increase in at least one other input. The radial (equiproportionate) nature of comparisons is clearly abandoned in the second of these notions. Evidently then, DebreuFarrell efficiency does not necessarily imply Pareto-Koopmans efficiency. Indeed, if slacks are present, the Debreu-Farrell approach may lead to an observation being compared to a reference DMU which is not Pareto-Koopmans efficient. The problem is somewhat mitigated by appending any slacks, weighted by the "infinitesimal" constant $\varepsilon$, to the value of the radial measure. It is known that this often employed solution does have some drawbacks. First, as in any practical application $\varepsilon$ must be given some value, it can give rise to computational problems [see Ali (1994)]. A second, more fundamental critique is that, though the use of $\varepsilon$ excludes Pareto-Koopmans dominated observations from being identified as efficient, it falls short in eliminating the total impact of slacks on the eventual efficiency scores. Especially when slacks are large and occur frequently they could influence the efficiency scores and rankings considerably, which in turn could result in wrong management conclusions. 
In some applications slacks indeed appear systematically while not being insignificantly small. In such cases it seems more appropriate to call for non-radial measures computed from comparison of each observation to a reference DMU which is not dominated in the Pareto-Koopmans sense. The Färe-Lovell (1978) and the Zieschang (1984) measures are two examples belonging to this class. A comparative study by Ferrier, Kerstens and Vanden Eeckaut (1994) shows that both measures have some favourable characteristics, making them a recommendable alternative for the radial measure when substantial amounts of slacks are present.

Ferrier, Kerstens and Vanden Eeckaut noted however another problem associated with the Färe-Lovell and Zieschang efficiency measures, viz. the fact that they, just as radial measures [see Thompson, Dharmapala and Thrall (1993)], cannot easily handle zero input and output data ${ }^{1}$. While at first sight a solution may be offered by affine displacements of the data, Ali and Seiford (1990) made clear that translation invariance pertains only to the classification of DMUs as efficient or inefficient. The actual efficiency scores and rankings can be altered. Moreover, this limited invariance only holds for models such as the BCC-model, containing a convexity constraint which reflects the assumption of variable returns to scale. These features carry over to the Färe-Lovell and the Zieschang classification.

A model that handles both the slack-problem and the occurrence of zeros in data is the additive model of Charnes et al. (1985), which we will discuss in somewhat more detail below. For the moment we point at some problems associated with the scores obtained from the additive DEA-model as it was originally formulated. First, unlike the DebreuFarrell measures the scores lack an attractive "degree" interpretation. They equal zero for an efficient observation and are negative for an inefficient observation. No dimensionless meaning attaches to the magnitude of the negative value, the latter being constructed as a sum of slacks. However, this can be and has been overcome by a particular rescaling of the scores (see below). A second inconvenience is that efficiency analysis based on this model is not 'oriented'. Unlike e.g. the BCC model, the original additive DEA model does not split up global efficiency of an observation into an input and output component. Pastor (1994) showed that this second drawback can easily be solved by a simple modification of the original additive model, which will be introduced in the next section.

We will use the latter modification to introduce an alternative relative (input and output) efficiency measure computed from the additive results. The associated efficiency scores can be decomposed in an appealing way. Specifically, they are the product of a classical radial measure and a factor that captures differences in input-outputmixes of an evaluated observation vis-à-vis its best practice reference. Thus, even if the nature of a dataset prevents or complicates the use of a Debreu-Farrell measure, related information can be obtained from a slack-based measure. Moreover, if the same dataset justifies the use of non-radial projections on the efficient frontier, this implies that an inefficient observation can in principle also learn from the input-output mix of its best practice

\footnotetext{
${ }^{1}$ In fact Färe, Lovell and Zieschang (1983) proposed a solution for the zero problem. The idea was to modify the measures so that any influence of zero dimensions on the efficiency measure was avoided. This implied, however, that the performance of different observations was measured relative to spaces of different dimensionality.
} 
reference observation. In general, aggregate information about the importance of the mix-deviation factor can be considered as an indicator of the dispersion between DebreuFarrell efficiency measurement and results obtained by referring to the Pareto-Koopmans efficiency notion. In the third section the output measure will be illustrated using the application of Nash and Sterna-Karwat (1996). The final section will reproduce our main findings and briefly comment on some possible generalizations.

\section{Proportional slack based measures: construction and interpretation}

As a preliminary step let us first consider the original additive model as it was formulated by Charnes, Cooper, Golany, Seiford and Stutz (1985). This model relates efficiency results to the notion of Pareto-Koopmans efficiency. Referring to the previous section, inefficiency in the Pareto-Koopmans sense implies that for the examined DMU there exists at least one other feasible input-output vector which weakly exceeds all of the DMU's output levels while simultaneously not using more of any of the DMU's input levels, with strict inequality of at least one component (input or output). The test for Pareto-Koopmans optimality for an observation $o$ thus amounts to solving the following linear program ${ }^{2}$ :

\section{Model 1 : Additive Model}

$$
\begin{gathered}
\min _{\lambda, s^{+}, s^{-}} z_{o}=-e^{T} s^{+}-e^{T} s^{-} \\
\text {such that: } \\
\mathbf{Y} \lambda-s^{+}=Y_{o} \\
-\mathbf{X} \lambda-s^{-}=-X_{o} \\
e^{T} \lambda=1 \\
\lambda, s^{+}, s^{-} \geq 0
\end{gathered}
$$

where $\mathbf{Y}$ is a non-negative output matrix and $\mathbf{X}$ a non-negative input matrix, with $i$ th columns $Y_{i}$ and $X_{i}$, respectively. The vectors $s^{+}$and $s^{-}$contain the output and input slacks. The vector $e^{T}$ is the sum vector.

Clearly the efficiency score, $z_{o}$, is exclusively composed of a sum of slacks. As such $z_{o}$ is not units invariant, a problem that can be solved by prescaling the data. A commonly used scaling procedure is to divide each input (or output) in a DMU's vector by the

\footnotetext{
${ }^{2}$ For the purpose of this paper it suffices to consider only the so-called envelopment formulation of the additive model. Note that one could equally well use the dual, "multiplier" formulation.
} 
average observed input (or output) in its category. The analysis can then be performed on the scaled data. This procedure boils down to substituting the objective function of model 1 by the following:

$$
\min _{\lambda, s^{+}, s^{-}} z_{o}=-e^{T} D_{y_{A}}^{-1} s^{+}-e^{T} D_{x_{A}}^{-1} s^{-}
$$

with $D_{y_{A}}$ and $D_{x_{A}}$ representing the diagonal matrices of output and input averages, respectively. Still, this formulation lacks the degree interpretation associated with the Debreu-Farrell measure. To obtain a relative score, the following measure, first proposed by Charnes, Cooper, Golany, Seiford and Stutz $\left(C^{2} G S^{2} ; 1984\right)$, can be computed from the additive results:

$$
C^{2} G S^{2}=\frac{e^{T} D_{y_{A}}^{-1} \mathbf{Y} \lambda^{*}+e^{T} D_{x_{A}}^{-1} \mathbf{X} \lambda^{*}}{e^{T} D_{y_{A}}^{-1} \mathbf{Y} \lambda^{*}+e^{T} D_{x_{A}}^{-1} \mathbf{X} \lambda^{*}+e^{T} D_{y_{A}}^{-1} s^{+*}+e^{T} D_{x_{A}}^{-1} s^{-*}}
$$

where the superscript $\left(^{*}\right)$ denotes an optimal value. Loosely speaking, the measure is computed as the 'sum of targets' divided by a sum of the 'sum of targets' and the 'sum of slacks' [see also Haag, Jaska and Semple (1992)]. The $C^{2} G S^{2}$ measure has the property that scores are 'dimensionless' in that they lie between zero and one.

Model 1 provides a measure for the overall efficiency of an observation. It is conceivable that in some applications one is interested in allowing for a separate reference point for input and output (in)efficiency. This information would be obtained by an input oriented and an output oriented additive model respectively [Pastor (1994)]. Essentially, this requires each observation to be compared with all Pareto-Koopmans efficient feasible inputoutput combinations that use at most the same amount of input (output orientation) and with all Pareto-Koopmans efficient members of the production set that produce at least the same amount of output (input orientation), respectively. Overall Pareto-Koopmans efficiency is achieved by an observation which is as well input as output efficient.

In a first step one should identify the Pareto-Koopmans efficient DMUs. To do so the original additive model should be applied. Suppose there are $N$ observations of which the additive model labels $i$ as efficient. Let us denote by $\mathbf{X}^{*}$ and $\mathbf{Y}^{*}$ the input and output matrices associated with these efficient observations. For each of the $N-i$ inefficient observations the following input and output oriented additive problems should then be solved: 
Model 2 :

\section{Input Oriented Additive Model}

$$
\min _{\lambda, s^{+}, s^{-}} z_{o}=-e^{T} s^{-}
$$

such that:

$$
\begin{gathered}
\mathbf{Y}^{*} \lambda-s^{+}=Y_{o} \\
-\mathbf{X}^{*} \lambda-s^{-}=-X_{o} \\
e^{T} \lambda=1
\end{gathered}
$$$$
\lambda, s^{+}, s^{-} \geq 0
$$

\section{Model 3 :}

\section{Output Oriented Additive Model}

$$
\min _{\lambda, s^{+}, s^{-}} z_{o}=-e^{T} s^{+}
$$

such that:

$$
\begin{gathered}
\mathbf{Y}^{*} \lambda-s^{+}=Y_{o} \\
-\mathbf{X}^{*} \lambda-s^{-}=-X_{o} \\
e^{T} \lambda=1 \\
\lambda, s^{+}, s^{-} \geq 0
\end{gathered}
$$

The input and output efficiency measures we present below are easily computed using the results of models 2 and 3 . We will first concentrate on the input measure, so as to sketch the basic intuition. Afterwards we will introduce and apply the output measure.

Solving model 2 results in an input efficiency rating which measures the maximum $\ell_{1}$ or one-norm distance that a particular DMU lies from the reference vector on the (input) efficiency frontier. The same reference vector is also used for determining our efficiency measure, which explains the "slack-basedness" appearing in the title of this paper. Now, however, we switch from the one-norm orientation to the more popular two-norm, $\ell_{2}$ or euclidean distance to arrive at a proportional measure. The input efficiency of an observation with input vector $x$ and slack vector $s^{-}$is then computed using the following simple formula:

$$
\frac{\left\|x_{R}\right\|}{\|x\|}=\frac{\sqrt{x_{R}^{T} x_{R}}}{\sqrt{x^{T} x}}, \text { with } x_{R}=x-s^{-}
$$

Like the Debreu-Farrell measure, (2) shows that the "degree" of inefficiency is computed by dividing two radial distances. However, the numerator is no longer found using equiproportionate input projections. Taken together it implies that the directions of the two radial vectors will in general not coincide. This deviation has a clear intuition, as we will now demonstrate.

In figure 1 an input vector $x_{a}(=(7,4))$ is drawn. Suppose that the additive model has selected vector $x_{b}(=(2,3))$ as its reference vector. The vectors $x_{a}$ and $x_{b}$ differ in two dimensions. First, there is the obvious fact that $x_{b}$ Pareto-dominates $x_{a}$. Second, the input mixes of $x_{a}$ and $x_{b}$ differ. Indeed, the proportion $\frac{x_{1}}{x_{2}}$ for $x_{a}$ is $\frac{7}{4}$ whereas it only amounts to $\frac{2}{3}$ for $x_{b}$. The latter results from different implicit cost price vectors, respectively $v_{a}(=(1,7 / 4))$ and $v_{b}(=(1,2 / 3))^{3}$.

Applying (2) yields an efficiency score of $44.72 \%$ for $x_{a}$. This score can be decomposed in two factors. To see this we first construct the lines perpendicular to the radials through

\footnotetext{
${ }^{3}$ The first input is taken as the numéraire.
} 
Figure 1: An illustrative example

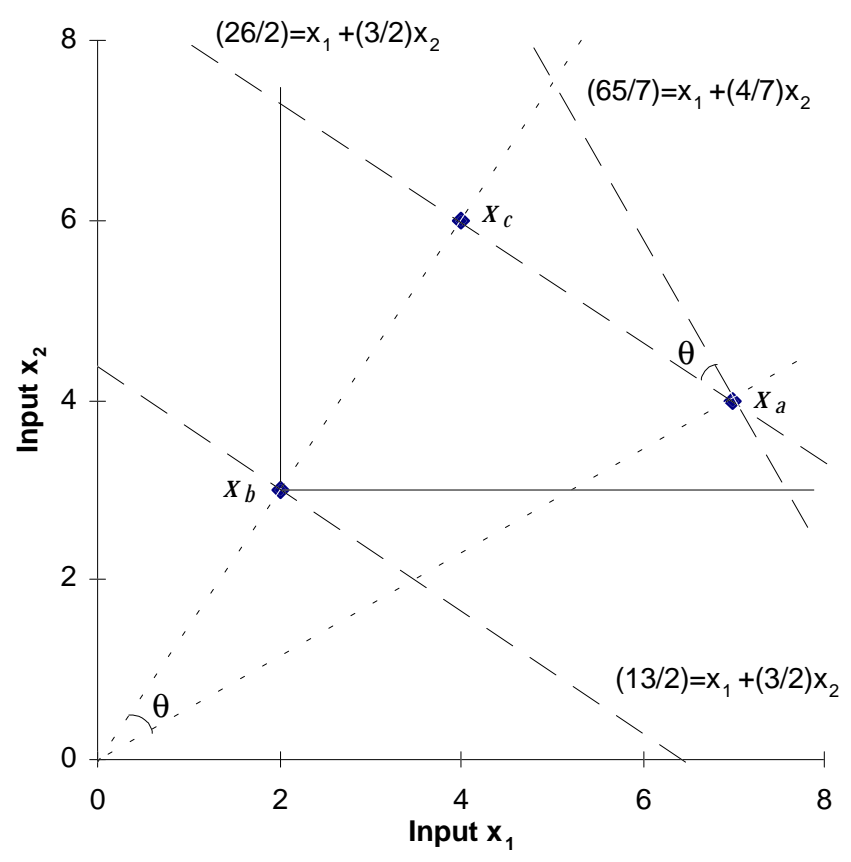

$x_{a}$ and $x_{b}$. These lines take the form $\beta_{i}=w_{i}^{T} x_{i}(i=a, b)$, with $w_{a}$ and $w_{b}$ equalling $(1,4 / 7)$ and $(1,3 / 2)$, respectively. Both perpendiculars are depicted in figure 1 , together with a line through $x_{a}$ which is parallel to the perpendicular through $x_{b}$. This allows us to identify $x_{c}$, which is the closest projection of $x_{a}$ on the radial through $x_{b}$.

In fact $x_{c}$ corrects for the deviation between $v_{a}$ and $v_{b}$. In order to get from $x_{a}$ to $x_{b}$ one first needs to adjust the input-mix $\left(x_{a} \rightarrow x_{c}\right)$, so as to apply an equiproportionate reduction of all inputs $\left(x_{c} \rightarrow x_{b}\right)$ afterwards. The inefficiency of $x_{a}$ thus results from (i) a deviation from the reference cost price vector and (ii) a cost level which is too high, even after adjustment for the implicit cost prices.

An appropriate measure for (i) is the cosine of the angle between the vectors $x_{b}$ (or $x_{c}$ ) and $x_{a}$. The ratio of the cost level of $x_{b}$ over the cost level of $x_{c}$ constitutes a measure for (ii). In fact, the latter is a measure for the ratio of minimal to actual costs after correction for the implicit price vector. This clearly refers to the cost interpretation of the radial efficiency measures stressed by Russell (1985). We can now decompose the input efficiency measure (2) as follows:

Proportional, Slack Based Input Efficiency Score for $x_{a}$

$$
\begin{aligned}
& \left.=\frac{\text { cost level } \mathrm{b}}{\text { cost level } \mathrm{c}} \times \cos \theta, \text { with } \theta \text { the angle between } x_{a} \text { and } x_{b} \text { (or } x_{c}\right) \\
& =\frac{w_{b}^{T} x_{b}}{w_{b}^{T} x_{a}} \times \frac{x_{a}^{T} x_{b}}{\left\|x_{a}\right\| \times\left\|x_{b}\right\|} \\
& =0.5 \times 0.8944
\end{aligned}
$$




$$
=44.72 \%
$$

The above example illustrates how the input efficiency measure (2) can be decomposed into two components. The first component captures the radial inefficiency due to a higher cost level after adjustment for the implicit vector (Debreu-Farrell component $(D F)$ ). The second component captures the inefficiency due to the deviation of the actual (implicit) cost price vector from the reference cost price vector (Implicit Price Correspondence component $(I P C))$. Its value will equal one if both cost price vectors coincide, and it will be lower as the price vectors deviate. Measure (2) thus expresses the idea that in a multiple input setting there are two sources of inefficiency. Indeed, efficiency does no longer only depend on a ratio between minimal to actual inputs but also on the proportion between the several inputs. Stated otherwise, as compared to the Debreu-Farrell measure the input-outputmixes of observations that are found to be inefficient (or equivalently, their implicit price vectors) are no longer sacrosanct when looking for a best practice reference DMU. Instead, the picture is reversed and inefficient DMUs can learn from the input-output mix of their identified reference DMUs.

In the general case the additive model will identify vector $x_{R}$ as the reference input vector for $x$. Denoting the vectors which define the perpendicular on the radials through $x$ and $x_{R}$ as respectively $w_{R}$ and $w$, we get:

$$
\text { Input Efficiency Measure }=\frac{\left\|x_{R}\right\|}{\|x\|}=\frac{w_{R}^{T} x_{R}}{w_{R}^{T} x} \times \frac{x^{T} x_{R}}{\|x\| \times\left\|x_{R}\right\|}
$$

An analogous formulation holds for the slack based output efficiency measure ${ }^{4}$ :

$$
\text { Output Efficiency Measure }=\frac{u_{R}^{T} y}{u_{R}^{T} y_{R}} \times \frac{y^{T} y_{R}}{\|y\| \times\left\|y_{R}\right\|}
$$

where $y$ and $y_{R}$ denote the actual and reference output vector, respectively. The vectors $u$ and $u_{R}$ define the perpendiculars on the radials. Note that these perpendiculars coincide with the implicit isorevenue lines, so that $u$ and $u_{R}$ are in fact implicit revenue price vectors. The interpretation of the output measure follows immediate. It is notably the output measure (4) which will be used in the next section.

\section{Application}

To illustrate the measure and its decomposition we will apply it on a problem taken from Nash and Sterna-Karwat (1996). These authors analysed the efficiency of financial product cross-selling for a sample of 75 bank branches. Cross-selling efficiency refers to the amount of related products that is sold with the sale of a major product. In the study housing loans were identified as being the major product. Four associated products

\footnotetext{
${ }^{4}$ Note that one cannot take $\frac{\|y\|}{\left\|y_{R}\right\|}$ as a measure for output efficiency as this ratio can be decomposed in the following way: $\frac{\|y\|}{\left\|y_{R}\right\|}=\frac{u_{R}^{T} y}{u_{R}^{T} y_{R}} \times\left[1 /\left(\frac{y^{T} y_{R}}{\|y\| \times y_{R} \|}\right)\right]$. Deviations from the reference output proportions would thus be rewarded, which is clearly undesirable.
} 
were selected. The ratio of each of these products over the amount of housing loans sold provides a partial measure of cross-selling efficiency. The Nash and Sterna-Karwat data are (also) reported in the appendix.

The sample has two particular features. First there are zeros in the data set as some branches did not cross-sell certain products during the period considered. This is a first reason why the popular radial models cannot be employed. But there is also a second reason why they do not seem appropriate. A number of branches perform relatively well on some products while there is only a poor performance with respect to other products. Obviously, in these cases it does seem hard to defend that a measure capturing the maximum equiproportionate expansion in all outputs will adequately reflect the overall relative cross-selling efficiency.

In a first exercise the original additive model was employed. From the additive results the $C^{2} G S^{2}$ scores were computed. It appeared that the many zeros in the data distorted the analysis of the branch cross-selling power considerably. Some branches entirely specialized in selling large amounts of two or three products. This feature apparently disadvantaged branches that provided each of the four products, as they were largely outperformed by linear combinations of specialized DMU's. No branch selling all four of the products was identified as being relatively efficient. Therefore, Nash and Sterna-Karwat introduced a modified additive model, designed so as to mitigate the impact of the many zero entries. A new 'output' was introduced in the form of a count of how many different types of products were sold by a branch over the period considered. Its value could range from 1 to 4 . If the corresponding 'counts'-vector is denoted by $c$ (with $c_{j}$ as its $j$ th element), the eventual model, which we will refer to as the "trade-off"-DEA model in the following, is model 1 (or, equivalently, model 3) with all reference to input being omitted and the following constraint included:

$$
c^{T} \lambda \geq c_{o}
$$

As noted by Nash and Sterna-Karwat, the idea here is that there exists a trade-off between offering more products and achieving high loan-product ratios for each of the products provided $^{5}$. The above restriction is important in so far that it restricts the set of potential reference points. The associated slack value is not captured by the objective function, however.

We also applied a third model to compute cross-selling efficiency scores, viz. the additive FDH model [see Bardhan et al. (1996)]. The applied model equals model 1 (or model 3) without references to input and adds to this the integrality constraint $\lambda_{j} \in\{0,1\}$ $(\forall j)$. Every inefficient observation is now compared to only one dominating observed output combination. This entails that an observation which provides, e.g., four products will be evaluated against an actually observed reference point providing all of the four products. The reference vector can no longer be a convex combination of two or more specialized observations. Clearly the FDH additive model is more generous than the two

\footnotetext{
${ }^{5}$ To some extent, this view can be reconciled with the argument of Byrnes, Färe and Grosskopf [1984] that zeros in data represent fundamental characterisations of the observed decision making process. There it is argued that a manager who does not use a particular input or produce a particular output has made a conscious decision choice to do so and that it is this decision choice which should be analysed.
} 
alternatives discussed above. All observations which are not strictly dominated in each of the four dimensions by an observed output vector will be labelled efficient.

$C^{2} G S^{2}$ output scores were computed for all three reference frontiers. Note that in this particular application formula (1) reduces to:

$$
C^{2} G S^{2}=\frac{e^{T} D_{y_{A}}^{-1} \mathbf{Y} \lambda^{*}}{e^{T} D_{y_{A}}^{-1} \mathbf{Y} \lambda^{*}+e^{T} D_{y_{A}}^{-1} s^{+*}},
$$

so that the 'sum of slacks' can at most equal the 'sum of targets'. Consequently the lower bound for the $C^{2} G S^{2}$ measure equals one half, which seems odd in comparison with other efficiency measures. While rescaling the scores is of course always a possibility, there is still no clear intuition for the cardinal $C^{2} G S^{2}$ scores. All that can be said a priori is that they equal one for efficient DMUs and that they will be lower the further an observation lies from its reference point. The $C^{2} G S^{2}$ output scores were compared with the efficiency scores obtained by the output oriented measure (4), and the two parts of which it is composed.

Table 1 provides some summary statistics about the $C^{2} G S^{2}$ and the price-adjusted proportional, slack based efficiency results (and their DF and IPC components) for each of the three models discussed above (respectively referred to as DEA, trade-off DEA and FDH). We find that the Spearman rank correlations are much higher for the FDH application than for the DEA and trade-off DEA applications. This contrasts with the overall score correlations, which are more or less the same. This result mainly follows from the fact that the DEA and trade-off DEA scores are mostly very low and for a great deal packed together, so that small shifts in scores may give rise to substantial shifts in rankings. The FDH scores, on the contrary, are more evenly distributed over the whole $[0,1]$-range resulting in less sensitive rankings.

Still other observations can be made from table 1, such as the relatively high average and minimum values associated with the FDH model, which reflect the generosity of the methodology. There is also the relatively low correlation between the $C^{2} G S^{2}$ and $I P C$ results. This finding has straightforward intuition as the $C^{2} G S^{2}$ measure only captures the (relative) distance from the target point and does not consider deviations from the target's implicit price vector.

Unlike the $C^{2} G S^{2}$ measure, the measure (4) also captures the deviation from the reference implicit price vector. Figure 2, which displays the histograms for the IPC components in the DEA, trade-off DEA and FDH applications, suggests that these price deviations can differ considerably across observations. It is seen that the most stringent model, the original DEA additive model, implies generally low IPC scores. Application of the most generous model, i.e. the additive FDH model, on the other hand, leads to higher $I P C$ scores. But even then price deviations are distributed over a substantially large range. In general, such results may act as a signal that, as far as the examined dataset is concerned, there is a wide dispersion between Debreu-Farrell efficiency measurement and results obtained by referring to the Pareto-Koopmans efficiency notion. 
Table 1: Summary statistics

\begin{tabular}{|lccc|}
\hline & DEA & trade-off DEA & FDH \\
\hline Scores correlation (Pearson): & & & \\
$C^{2} G S^{2}$-price-adjusted & 0.9890 & 0.9859 & 0.9808 \\
$C^{2} G S^{2}-D F$ & 0.9913 & 0.9861 & 0.9812 \\
$C^{2} G S^{2}-I P C$ & 0.4965 & 0.6437 & 0.6179 \\
\hline Rankings correlation (Spearman): & & & \\
$C^{2} G S^{2}$-price-adjusted & 0.2701 & 0.7590 & 0.9557 \\
$C^{2} G S^{2}-D F$ & 0.5377 & 0.8336 & 0.9714 \\
$C^{2} G S^{2}-I P C$ & -0.0137 & 0.6050 & 0.8761 \\
\hline Standard deviation of scores: & & & \\
$C^{2} G S^{2}$ & 0.1092 & 0.1479 & 0.1971 \\
price-adjusted & 0.2258 & 0.3216 & 0.4064 \\
$D F$ & 0.2263 & 0.3167 & 0.3957 \\
IPC & 0.2980 & 0.3180 & 0.2090 \\
\hline Average score value: & & & \\
$C^{2} G S^{2}$ & 0.5522 & 0.6051 & 0.7108 \\
price-adjusted & 0.0692 & 0.1779 & 0.4449 \\
$D F$ & 0.0817 & 0.2019 & 0.4617 \\
$I P C$ & 0.3799 & 0.5251 & 0.8380 \\
\hline Minimum score value: & & & \\
$C^{2} G S^{2}$ & 0.5063 & 0.5202 & 0.5216 \\
price-adjusted & 0.0002 & 0.0009 & 0.0151 \\
DF & 0.0026 & 0.0090 & 0.0378 \\
IPC & 0.0605 & 0.0985 & 0.2947 \\
\hline
\end{tabular}

Analysing the price deviations somewhat further, we find for the DEA model and (to a somewhat lesser extent) for the trade-off version that especially the implicit price deviations for the fourth product are substantial (see figure 3, where output 2 is taken as the numéraire). This mainly follows from the fact that one observation (branch 3 ), which provided only two products, is heavily specialised in the fourth product. When searching for reference output combinations for inefficient DMUs, the weight attributed to this observation is generally high, which causes considerable differences between actual and reference implicit prices for the fourth product. On the other hand, the FDH model does not allow to compare with linear combinations of efficient DMUs. Only actually observed combinations can be used as reference points. The highly specialised DMU thus only constitutes a possible reference for similarly specialized branches. Apparently this applies for only two observations (44 and 61).

Let us, finally, take a closer look at some individual results. The appendix gives the FDH results for the whole set of DMUs. Consider branch 18 which is compared to observation 11. This observation has a moderate $D F$ score of 69 percent. Its $I P C$ score, on the contrary, amounts to 98 percent. Indeed, the output proportions of observation 18 are close to the reference output proportions. This is hardly the case for observation 57 , which is dominated by observation 4 . The low IPC score can be explained by the 
Figure 2: Histograms implicit price correspondence (IPC) components

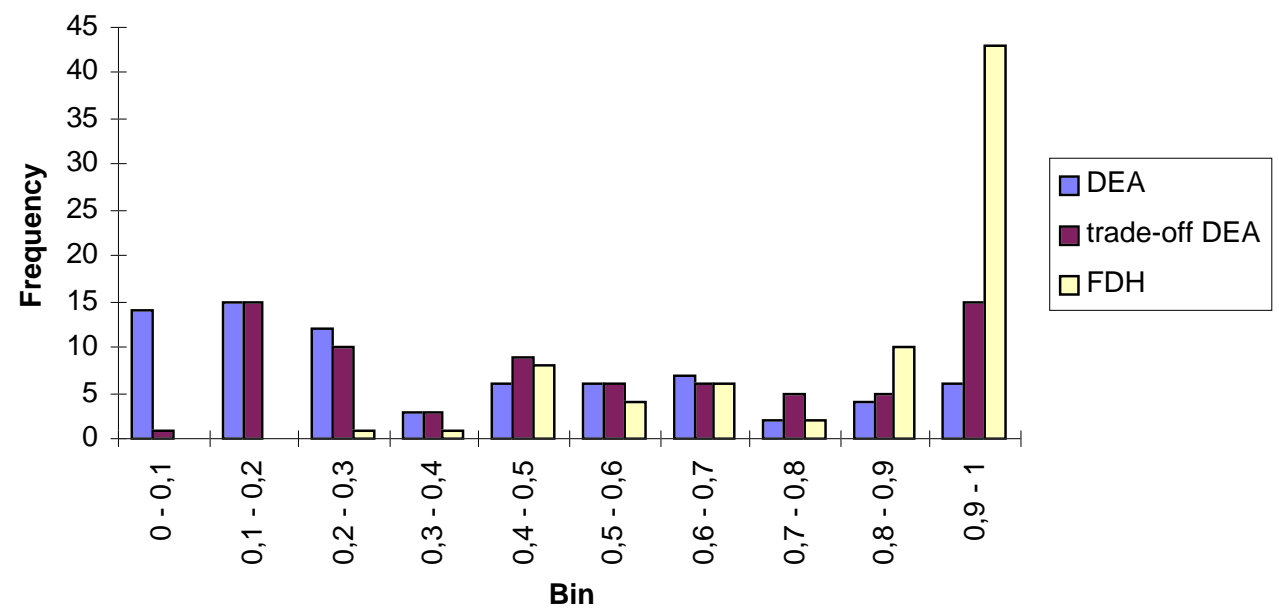

Figure 3: Differences between own and reference implicit prices (product 4)

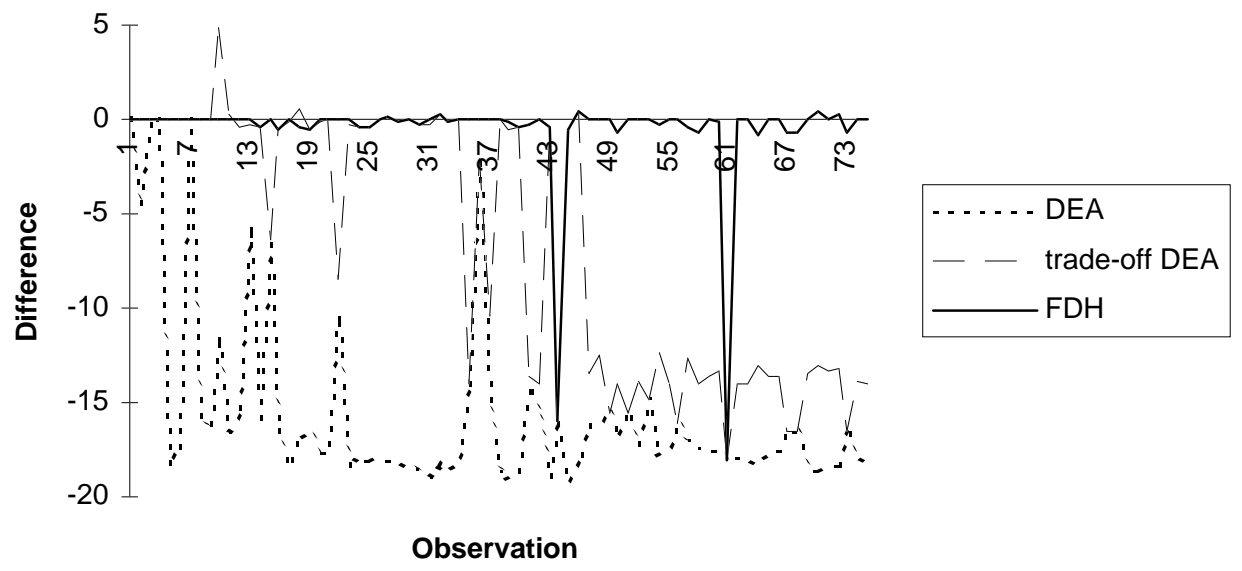


fact that branch 4 , while attaining only moderately higher values for the product ratios 1, 2 and 4, achieves a very high cross-selling ratio for product 3, which is not provided by DMU 57. The 'mix efficiency' of the latter is therefore very low. Observation 48, which has 1 as reference branch, does not deviate much from its best practice peer w.r.t. the relative product prices that underly the observed mix. The Debreu-Farrell distance from the reference point (after correction for the implicit prices) is considerable, however. In this respect, branch 15, which shares the same reference observation, fares much better. Observation 48 could also be compared to branch 14. Both have bad scores on the "leveltest", but branch 48 performs better w.r.t. mimicking the output-composition of its best practice reference. Such examples indicate that both components of the measure may provide the researcher with interesting information about (i) whether radial measurement would yield results that deviate to a considerable extent from Pareto-Koopmans efficiency measurement, and (ii) the inefficiency of a DMU in relation to its reference observation, both in terms of input/output composition as well as in level terms.

\section{Comments and conclusion}

While radial efficiency measures possess an attractive interpretation, they do not always conform to the Koopmans definition of technical efficiency. Moreover, in many cases, such as the classical CCR and BCC model formulations, strictly positive data entries are required throughout the complete data domain. Both of these problems restrict their field of applicability.

A model which does not face the above difficulties is the additive model. The associated score lacks an intuitive interpretation, however. Therefore we introduced another efficiency measure which is constructed from the additive results. In this paper we proposed to solve an (input- or output-) oriented additive model in a first step. Note that this is not strictly necessary -one could equally well compute input and output scores directly from the original additive results- but it allows to identify different reference sets according to the orientation.

The measure discussed in this paper, which has both an input and an output version, can be decomposed into a Debreu-Farrell and an implicit price correspondence component. As we tried to made clear using the Nash and Sterna-Karwat (1996) application, both components offer information that can be interesting when evaluating productive activities.

While we have opted to introduce this measure using an oriented additive model, we note here that in general such a decomposable measure need not necessarily be slack based. In fact it can be computed as soon as one disposes of a reference point for the DMU under study. One could, for instance, first identify the reference point used to calculate the Färe-Lovell (1978) or Zieschang (1984) efficiency score and compute a measure similar to (4) or (5) in a second step. Especially when the reference price vector differs from the actual implicit price vector (i.e. when the reference DMU does not coincide with an equiproportionate projection) the measure presented here captures useful information precisely on the deviation between these implicit relative prices (and their associated 
input-outputmixes).

Of course, DEA is an efficiency measurement tool rather than a panacea. Options concerning the choice of measure(s) or assumptions on the reference technology are finally in the hands of the evaluator, who should therefore have an eye for the particular problem and data at hand. This is all the more true if one recognizes, as in our example, the substantial impact of such options on the eventual efficiency scores and, consequently, on the possible management conclusions.

\section{References}

[1] ALI, A. (1994), Computational Aspects of DEA, in: CHARNES, A., COOPER, W.W., LEWIN, A.Y. and L.M. SEIFORD (eds.), Data Envelopment Analysis: Theory, Methodology and Applications, Kluwer Academic Publishers, Boston/Dordrecht/London, p. 63-88.

[2] ALI, A and L.M. SEIFORD (1990), Translation Invariance in Data Envelopment Analysis, Operations Research Letters 9, p 403-405.

[3] BANKER, R.D., CHARNES, A. and W.W. COOPER (1984), Some Models for Estimating Technical and Scale Inefficiencies in Data Envelopment Analysis, Management Science 30 (9), p. 1078-1092.

[4] BARDHAN, I., BOWLIN, W.F., COOPER, W.W. and T. SUEYOSHI (1996), Models and Measures for Efficiency Dominance in DEA: Part I: Additive Models and MED Measures, Journal of Operations Research Society of Japan 39, p. 322-332.

[5] BYRNES, P., FÄRE, R. and S. GROSSKOPF (1984), Measuring Productive Efficiency: an Application to Strip Mines, Management Science 30, p. 671-681.

[6] CHARNES, A., COOPER, W.W. and E. RHODES (1978), Measuring the Efficiency of Decision Making Units, European Journal of Operational Research 2, p. 429-444.

[7] CHARNES, A., COOPER, W.W. and E. RHODES (1979), Measuring the Efficiency of Decision Making Units, European Journal of Operational Research 3, p. 239.

[8] CHARnes, A., COOPER, W.W., GOLANY, B., SEIFORD, L. and J. STUTZ (1984), A Dimensionless Measure for Departures from Pareto Optimality, CCS Research Report 480, University of Texas, Austin.

[9] CHARneS, A., COOPER, W.W., GOLANy, B., SEIFORD, L. and J. STUTZ (1985), Foundations of Data Envelopment Analysis for Pareto-Koopmans Efficient Empirical Production Functions, Journal of Econometrics 30 (1/2), p. 91-107.

[10] DEBREU, G. (1951), The Coefficient of Resource Utilisation, Econometrica 19(3), p. $273-292$. 
[11] FÄRE, R. and C.A.K. LOVELL (1978), Measuring the Technical Efficiency of Production, Journal of Economic Theory 19 (1), p. 150-162.

[12] FÄRE, R., LOVELL, C.A.K. and K. ZIESCHANG (1983), Measuring the Technical Efficiency of Multiple Output Production Technologies, in: EICHHORN, W., NEUMANN, K. and R. SHEPHARD (eds.), Quantitative Studies on Production and Prices, Physica-Verlag, Würzburg, p. 150-171.

[13] FARRELL, M.J. (1957), The Measurement of Productive Efficiency, Journal of the Royal Statistical Society Series A 120 (3), p 253-281.

[14] FERRIER, G.D., KERSTENS, K. and P. VANDEN EECKAUT (1994), Radial and Non-radial Technical Efficiency Measures on a DEA Reference Technology: a Comparison Using US Banking Data, Recherches Economiques de Louvain 60 (4), p. 449-479.

[15] HAAG, S., JASKA, P. and J. SEMPLE (1992), Assessing the Relative Efficiency of Agricultural Production Units in the Backland Prairie, Texas, Applied Economics 24, p. 559-565.

[16] KOOPMANS, T. (1951), Analysis of Production as an Efficient Combination of Activities, in: KOOPMANS, T. (ed.), Activity Analysis of Production and Allocation: Proceedings of a Conference, Yale University Press, New Haven, p. 33-97.

[17] NASH, D. and A. STERNA-KARWAT (1996), An Application of DEA to Measure Branch Cross Selling Efficiency, Computers and Operations Research 23 (4), p. 385392.

[18] PASTOR J.T. (1994), New Additive Models for Handling Zero and Negative Data, paper presented at the Alaska TIMS meeting, Anchorage.

[19] RUSSELL, R. (1985), Measures of Technical Efficiency, Journal of Economic Theory 35(1), p.109-126

[20] THOMPSON, R.G., DHARMAPALA, P.S. and R.M. THRALL (1993), Importance for DEA of Zeros in Data, Multipliers and Solutions, Journal of Productivity Analysis 4, p. 339-390.

[21] ZIESCHANG, K. (1984), An Extended Farrell Efficiency Measure, Journal of Economic Theory 33 (2), p. 387-396. 


\section{Appendix: Data and FDH results}

\begin{tabular}{|c|c|c|c|c|c|c|c|c|c|c|c|}
\hline & Product 1 & & Product 2 & & Product 3 & & Product 4 & & Score & & \\
\hline Branch & Actual & Reference & Actual & Reference & Actual & Reference & Actual & Reference & DF & PD & slack based \\
\hline 1 & 1176 & 1176 & 158 & 158 & 183 & 183 & 0 & 0 & 1,0000 & 1,0000 & 1,0000 \\
\hline 2 & 255 & 255 & 297 & 297 & 0 & 0 & 125 & 125 & 1,0000 & 1,0000 & 1,0000 \\
\hline 3 & 0 & 0 & 198 & 198 & 0 & 0 & 3900 & 3900 & 1,0000 & 1,0000 & 1,0000 \\
\hline 4 & 215 & 215 & 85 & 85 & 767 & 767 & 62 & 62 & 1,0000 & 1,0000 & 1,0000 \\
\hline 5 & 77 & 77 & 168 & 168 & 31 & 31 & 38 & 38 & 1,0000 & 1,0000 & 1,0000 \\
\hline 6 & 158 & 158 & 126 & 126 & 12 & 12 & 19 & 19 & 1,0000 & 1,0000 & 1,0000 \\
\hline 7 & 0 & 0 & 465 & 465 & 79 & 79 & 0 & 0 & 1,0000 & 1,0000 & 1,0000 \\
\hline 8 & 120 & 120 & 82 & 82 & 49 & 49 & 156 & 156 & 1,0000 & 1,0000 & 1,0000 \\
\hline 9 & 85 & 85 & 86 & 86 & 61 & 61 & 146 & 146 & 1,0000 & 1,0000 & 1,0000 \\
\hline 10 & 80 & 80 & 22 & 22 & 67 & 67 & 146 & 146 & 1,0000 & 1,0000 & 1,0000 \\
\hline 11 & 57 & 57 & 73 & 73 & 68 & 68 & 139 & 139 & 1,0000 & 1,0000 & 1,0000 \\
\hline 12 & 94 & 94 & 87 & 87 & 259 & 259 & 20 & 20 & 1,0000 & 1,0000 & 1,0000 \\
\hline 13 & 0 & 0 & 57 & 57 & 24 & 24 & 780 & 780 & 1,0000 & 1,0000 & 1,0000 \\
\hline 14 & 215 & 215 & 85 & 85 & 87 & 767 & 27 & 62 & 0,1887 & 0,6103 & 0,1152 \\
\hline 15 & 851 & 1176 & 112 & 158 & 0 & 183 & 0 & 0 & 0,7066 & 0,9883 & 0,6983 \\
\hline 16 & 125 & 215 & 66 & 85 & 152 & 767 & 16 & 62 & 0,2324 & 0,8971 & 0,2085 \\
\hline 17 & 41 & 41 & 119 & 119 & 72 & 72 & 28 & 28 & 1,0000 & 1,0000 & 1,0000 \\
\hline 18 & 53 & 57 & 53 & 73 & 65 & 68 & 80 & 139 & 0,6897 & 0,9759 & 0,6730 \\
\hline 19 & 14 & 215 & 57 & 85 & 232 & 767 & 6 & 62 & 0,2884 & 0,9679 & 0,2791 \\
\hline 20 & 100 & 100 & 92 & 92 & 41 & 41 & 42 & 42 & 1,0000 & 1,0000 & 1,0000 \\
\hline 21 & 39 & 215 & 77 & 85 & 105 & 767 & 57 & 62 & 0,1533 & 0,8360 & 0,1282 \\
\hline 22 & 501 & 501 & 66 & 66 & 203 & 203 & 0 & 0 & 1,0000 & 1,0000 & 1,0000 \\
\hline 23 & 59 & 59 & 109 & 109 & 40 & 40 & 25 & 25 & 1,0000 & 1,0000 & 1,0000 \\
\hline 24 & 55 & 215 & 58 & 85 & 90 & 767 & 21 & 62 & 0,1349 & 0,8870 & 0,1197 \\
\hline 25 & 90 & 215 & 79 & 85 & 37 & 767 & 23 & 62 & 0,0865 & 0,5457 & 0,0472 \\
\hline 26 & 78 & 215 & 61 & 85 & 21 & 767 & 43 & 62 & 0,0631 & 0,4609 & 0,0291 \\
\hline 27 & 43 & 215 & 63 & 85 & 29 & 767 & 59 & 62 & 0,0627 & 0,5006 & 0,0314 \\
\hline 28 & 35 & 215 & 59 & 85 & 61 & 767 & 37 & 62 & 0,0955 & 0,7749 & 0,0740 \\
\hline 29 & 32 & 215 & 69 & 85 & 30 & 767 & 52 & 62 & 0,0604 & 0,5007 & 0,0302 \\
\hline 30 & 33 & 215 & 73 & 85 & 47 & 767 & 35 & 62 & 0,0798 & 0,6460 & 0,0516 \\
\hline 31 & 29 & 77 & 97 & 168 & 25 & 31 & 25 & 38 & 0,5540 & 0,9878 & 0,5473 \\
\hline 32 & 17 & 215 & 53 & 85 & 27 & 767 & 54 & 62 & 0,0499 & 0,4883 & 0,0244 \\
\hline 33 & 25 & 215 & 71 & 85 & 16 & 767 & 46 & 62 & 0,0411 & 0,3683 & 0,0151 \\
\hline 34 & 41 & 215 & 54 & 85 & 17 & 767 & 40 & 62 & 0,0448 & 0,4470 & 0,0200 \\
\hline 35 & 92 & 92 & 122 & 122 & 374 & 374 & 0 & 0 & 1,0000 & 1,0000 & 1,0000 \\
\hline 36 & 0 & 0 & 408 & 465 & 0 & 79 & 0 & 0 & 0,8528 & 0,9859 & 0,8408 \\
\hline 37 & 327 & 1176 & 150 & 158 & 21 & 183 & 0 & 0 & 0,2859 & 0,9525 & 0,2723 \\
\hline 38 & 10 & 215 & 61 & 85 & 23 & 767 & 48 & 62 & 0,0433 & 0,4265 & 0,0185 \\
\hline 39 & 35 & 77 & 101 & 168 & 14 & 31 & 7 & 38 & 0,5570 & 0,9858 & 0,5491 \\
\hline 40 & 42 & 215 & 55 & 85 & 34 & 767 & 17 & 62 & 0,0633 & 0,6437 & 0,0407 \\
\hline 41 & 0 & 215 & 72 & 85 & 359 & 767 & 28 & 62 & 0,4387 & 0,9599 & 0,4211 \\
\hline 42 & 75 & 92 & 87 & 122 & 311 & 374 & 0 & 0 & 0,8199 & 0,9991 & 0,8192 \\
\hline 43 & 29 & 215 & 63 & 85 & 23 & 767 & 21 & 62 & 0,0473 & 0,4998 & 0,0236 \\
\hline 44 & 0 & 0 & 102 & 198 & 0 & 0 & 378 & 3900 & 0,0980 & 0,9774 & 0,0958 \\
\hline 45 & 11 & 215 & 84 & 85 & 29 & 767 & 18 & 62 & 0,0509 & 0,4478 & 0,0228 \\
\hline 46 & 28 & 215 & 25 & 85 & 19 & 767 & 27 & 62 & 0,0378 & 0,6073 & 0,0229 \\
\hline 47 & 0 & 0 & 88 & 88 & 236 & 236 & 42 & 42 & 1,0000 & 1,0000 & 1,0000 \\
\hline 48 & 215 & 1176 & 28 & 158 & 87 & 183 & 0 & 0 & 0,1895 & 0,9740 & 0,1846 \\
\hline 49 & 0 & 0 & 148 & 148 & 304 & 304 & 0 & 0 & 1,0000 & 1,0000 & 1,0000 \\
\hline 50 & 84 & 215 & 77 & 85 & 203 & 767 & 0 & 62 & 0,2793 & 0,9640 & 0,2692 \\
\hline 51 & 0 & 0 & 132 & 148 & 304 & 304 & 0 & 0 & 0,9793 & 0,9991 & 0,9784 \\
\hline 52 & 116 & 1176 & 137 & 158 & 117 & 183 & 0 & 0 & 0,1245 & 0,6976 & 0,0869 \\
\hline 53 & 341 & 1176 & 87 & 158 & 0 & 183 & 0 & 0 & 0,2877 & 0,9816 & 0,2825 \\
\hline 54 & 0 & 120 & 76 & 82 & 37 & 49 & 120 & 156 & 0,5592 & 0,8335 & 0,4661 \\
\hline 55 & 67 & 1176 & 68 & 158 & 172 & 183 & 0 & 0 & 0,0840 & 0,5124 & 0,0430 \\
\hline 56 & 0 & 92 & 110 & 122 & 270 & 374 & 0 & 0 & 0,7009 & 0,9712 & 0,6807 \\
\hline 57 & 177 & 215 & 70 & 85 & 0 & 767 & 22 & 62 & 0,0703 & 0,2947 & 0,0207 \\
\hline 58 & 46 & 215 & 54 & 85 & 186 & 767 & 0 & 62 & 0,2434 & 0,9825 & 0,2391 \\
\hline 59 & 137 & 1176 & 108 & 158 & 55 & 183 & 0 & 0 & 0,1306 & 0,8572 & 0,1119 \\
\hline 60 & 137 & 255 & 108 & 297 & 0 & 0 & 28 & 125 & 0,4176 & 0,9712 & 0,4055 \\
\hline 61 & 0 & 0 & 132 & 198 & 0 & 0 & 208 & 3900 & 0,0549 & 0,8704 & 0,0478 \\
\hline 62 & 52 & 1176 & 85 & 158 & 136 & 183 & 0 & 0 & 0,0690 & 0,4914 & 0,0339 \\
\hline 63 & 79 & 1176 & 104 & 158 & 96 & 183 & 0 & 0 & 0,0880 & 0,6521 & 0,0574 \\
\hline 64 & 0 & 85 & 85 & 86 & 51 & 61 & 79 & 146 & 0,5536 & 0,8698 & 0,4815 \\
\hline 65 & 130 & 1176 & 106 & 158 & 35 & 183 & 0 & 0 & 0,1221 & 0,8557 & 0,1045 \\
\hline 66 & 137 & 1176 & 54 & 158 & 55 & 183 & 0 & 0 & 0,1247 & 0,9522 & 0,1187 \\
\hline 67 & 0 & 215 & 79 & 85 & 243 & 767 & 0 & 62 & 0,2991 & 0,9405 & 0,2813 \\
\hline 68 & 0 & 215 & 70 & 85 & 246 & 767 & 0 & 62 & 0,3015 & 0,9471 & 0,2855 \\
\hline 69 & 0 & 0 & 118 & 118 & 64 & 64 & 56 & 56 & 1,0000 & 1,0000 & 1,0000 \\
\hline
\end{tabular}




\begin{tabular}{|c|c|c|c|c|c|c|c|c|c|c|c|}
\hline & Product 1 & & Product 2 & & Product 3 & & Product 4 & & Score & & \\
\hline Branch & Actual & Reference & Actual & Reference & Actual & Reference & Actual & Reference & DF & PD & slack based \\
\hline 70 & 15 & 255 & 100 & 297 & 0 & 0 & 89 & 125 & 0,2644 & 0,8066 & 0,2133 \\
\hline 71 & 56 & 1176 & 148 & 158 & 76 & 183 & 0 & 0 & 0,0716 & 0,4894 & 0,0350 \\
\hline 72 & 47 & 255 & 89 & 297 & 0 & 0 & 67 & 125 & 0,2771 & 0,9418 & 0,2610 \\
\hline 73 & 0 & 215 & 40 & 85 & 243 & 767 & 0 & 62 & 0,2940 & 0,9591 & 0,2819 \\
\hline 74 & 116 & 1176 & 76 & 158 & 47 & 183 & 0 & 0 & 0,1089 & 0,8932 & 0,0973 \\
\hline 75 & 108 & 1176 & 118 & 158 & 33 & 183 & 0 & 0 & 0,1052 & 0,7736 & 0,0814 \\
\hline
\end{tabular}




\section{DISCUSSION PAPERS 1997}

DPS 97.01 Hans Dewachter, Geert Gielens and Dirk Veestraeten, An Assessment of Central Banks.' Stand on Exchange Rate Stabilization Policies, February. (International Economics).

DPS 97.02 Anneleen Peeters, How Hiring and Firing Costs Affect Labour Demand in a Model of Uncertainty, February. (International Economics).

DPS 97.03 Hans Eyssen, Are West-African Immigrants Discriminated in Cote DIvoire?, March. (Development Economics).

DPS 97.04 Wim Lagae, The Absorption of the Effects of Debt Relief Operations by European Export Credit Agencies: An Institutional Analysis, March. (Development Economics).

DPS 97.05 Jenke ter Horst and Marno Verbeek, Estimating Short-Run Persistence in Mutual Fund Performance, March. (Econometrics).

DPS 97.06 Hans Dewachter and Hanno Lustig, A Cross-Country Comparison of CPI as a Measure of Inflation, April. (Financial Economics).

DPS 97.07 Yunus Aksoy and Yohanes E. Riyanto, Exchange Rate Pass-Through in Vertically Related Markets, May. (International Economics).

DPS 97.08 Paul De Grauwe, The Indeterminacy of the Euro Conversion Rates. Why it Matters and how it can be solved, June. (International Economics).

DPS 97.09 Jozef Konings, Hylke Vandenbussche and Reinhilde Veugelers, Union Wage Bargaining and European Antidumping Policy, June (Financial Economics).

DPS 97.10 Francis Vella and Marno Verbeek, Using Rank Order as an Instrumental Variable: An Application to the Return to Schooling, May. (Econometrics).

DPS 97.11 Jozef Konings and Patrick P. Walsh, The Effect of Real Exchange Rate Movements and Ownership on the Life Cycle of Manufacturing Plants in Ireland (1973-1994), June. (Financial Economics).

DPS 97.12 Johan Eyckmans, Balancedness of games with multilateral environmental externalities, August. (Public Economics).

DPS 97.13 Patrick Van Cayseele and Dave FURTH, Price Leadership and Buyouts, September. (Financial Economics).

DPS 97.14 Mark De Broeck, Dominique Guillaume and Emmanuel Van der Stichele, Small and Big Bangs in Bond Markets, September (Financial Economics).

DPS 97.15 Hanno Lustig, Re-examining the Synchronization of European Business Cycles, September (Financial Economics).

DPS 97.16 Jõ̃ P. Cocco, Francisco J. Gomes and Pascal J. Maenhout, A Two-Period Model of Consumption and Portfolio Choice With Incomplete Markets, June (Financial Economics). 
DPS 97.17 Stefan Dercon and Daniel Ayalew, Demobilisation and Reintegration of ExSoldiers in Ehtiopia, October (Development Economics).

DPS 97.18 Stefan Dercon and Pramila Krishnan, In Sickness and in HealthRisk-Sharing within Households in Rural Ethiopia, October (Development Economics).

DPS 97.19 Paul Collier, Stefan Dercon and John Mackinnon, Density versus Quality in Health Care Provision: The Use of Household Data for Budgetary Choices in Ehtiopia October (Development Economics).

DPS 97.20 van der Lijn Nick and Marno Verbeek, Excess demand, repressed inflation, and forced saving in the Soviet Union, October (Econometrics).

DPS 97.21 Lorelei Crisologo-Mendoza and Dirk Van de gaer, Population Growth and Customary Law on Land: The Case of Cordillera Villages in the Philippines, October (Development Economics).

DPS 97.22 Tom Van Puyenbroeck, Two-stage optimal control problems subject to an isoperimetric constraint, October (Public Economics).

DPS 97.23 Erik Schokkaert, Geert Dhaene and Carine Van de Voorde, Risk Adjustment and the Trade-off Between Efficiency and Risk Selection, November (Public Economics).

DPS 97.24 Paul De Grauwe, Hans Dewachter and Dirk Veestraeten, Stochastic Process Switching and Stage III of EMU, November (International Economics).

DPS 97.25 Dirk Heremans, Regulation of Banking and Financial Intermediation, November (Financial Economics).

DPS 97.26 Knud J. Munk, Agricultural Policy a Public Economic Explanation, November (Public Economics).

DPS 97.27 Hans Dewachter, Can Markov Switching Models Replicate Chartist Profits in the Foreign Exchange Market? November (International Economics).

DPS 97.28 Paul De Grauwe and Frauke Skudelny, The Impact of EMU on Trade Flows, December (International Economics). 


\section{DISCUSSION PAPERS 1998}

DPS 98.01 Louis Baeck, Thematisation and Canon Building in Post-War Development Studies, January (Development Economics).

DPS 98.02 Hans Dewachter and Hanno Lustig, Sticky Prices and the Nominal Effects of Real Shocks, January (International Economics).

DPS 98.03 Ilse Frederickx, Health in Rural Tanzania: The Determinants of Health Status, Health Care Demand and Health Care Choice, January (Development Economics).

DPS 98.04 Paul De Grauwe, European Unemployment. A Tale of Demand and Supply, February (International Economics).

DPS 98.05 Jo旡 Cocco, Francisco Gomes and Pascal Maenhout, Consumption and Portfolio Choice over the Life-Cycle, March (Financial Economics).

DPS 98.06 Yunus Aksoy and Hanno Lustig, Circular Aspects of Exchange Rates and Market Structure, January (International Economics).

DPS 98.07 André Decoster and Frederic Vermeulen, Evaluation of the Empirical Performance of Two-Stage Budgeting AIDS, QUAIDS and Rotterdam Models Based on Weak Separability, April (Public Economics).

DPS 98.08 Erik Schokkaert and Luc Van Ootegem, Preference Variation and Private Donations, April (Public Economics).

DPS 98.09 Erik Schokkaert, Mr. Fairmind is Post-Welfarist: Opinions on Distributive Justice, April (Public Economics).

DPS 98.10 Dirk Van de gaer, Michel Martinez and Erik Schokkaert, Measuring Intergenerational Mobility and Equality of Opportunity, April (Public Economics).

DPS 98.11 Paulo Augusto Nunes, Testing the Validity of WTP values from a Contingent Valuation Survey in Portugal, April (Public Economics).

DPS 98.12 Paulo Augusto Nunes, Measuring the WTP for Recreation and Biodiversity Protection Programs, April (Public Economics).

DPS 98.13 Laurens Cherchye and Tom Van Puyenbroeck, Learning from Input-Output Mixes in DEA: A Proportional Measure for Slack-Based Efficient Projections, February (Public Economics).

DPS 98.14 Jerzy Mycielski and Yohanes Riyanto, On the Interaction between Taste and Distance and Its Implications on the Vertical Distribution Arrangement, May (Financial Economics).

DPS 98.15 Jerzy Mycielski, Yohanes Riyanto and Filip Wuyts, Product Differentiation and the Equilibrium Structure of the Manufacturer-Retailer Relationship, May (Financial Economics). 
DPS 98.16 Hans Degryse and Patrick Van Cayseele, Relationship Lending within a Bankbased System: Evidence from European Small Business Data, April (Financial Economics).

DPS 98.17 Pramila Krishnan, Tesfaye Gebre Selassie and Stefan Dercon, The Urban Labour Market During Structural Adjustment: Ethiopia 1990-1997, April (Development Economics).

DPS 98.18 Bart Capáu and Stefan Dercon, Prices, Local Measurement Units and Subsistence Consumption in Rural Surveys: An Econometric Approach with an Application to Ethiopia, March (Development Economics).

DPS 98.19 Stefan Dercon and Pramila Krishnan, Changes in Poverty in Rural Ethiopia 1989-1995: Measurement, Robustness Tests and Decomposition, March (Development Economics).

DPS 98.20 Jenke R. ter Horst, Theo E. Nijman and Marno Verbeek, Eliminating Biases in Evaluating Mutual Fund Performance from a Survivorship Free Sample, June (Econometrics).

DPS 98.21 Hilke Vandenbussche and Jozef Konings, Globalization and the effects of national versus international competition on the labour market. Theory and evidence from Belgian firm level data, August (Financial Economics).

DPS 98.22 Wim Moesen and Laurens Cherchye, The Macroeconomic Performance of Nations Measurement and Perception, August (Public Economics).

DPS 98.23 Anneleen Peeters, Interim Employment and a Leading Indicator for the Belgian Labour Market, September (International Economics, IERP 137).

DPS 98.24 Wessel Marquering and Marno Verbeek, An Empirical Analysis of Intertemporal Asset Pricing Models with Transaction Costs and Habit Persistence, September (Econometrics).

DPS 98.25 Filip Abraham and Joeri Van Rompuy, Is Belgium ready for EMU? A look at national, sectoral and regional developments, September (International Economics, IERP 138).

DPS 98.26 Sara Ochelen, Stef Proost and Kurt Van Dender, Optimal Pricing for Urban Road Transport Externalities, September (Public Economics).

DPS 98.27 Knud Munk, Optimal Support to Low-skilled Households, July (Public Economics).

DPS 98.28 Wim Moesen and Philippe Van Cauwenberge, The Status of the Budget Constraint, Federalism and the Relative Size of Government: A Bureaucracy Approach, September (Public Economics).

DPS 98.29 Laurens Cherchye, The Measurement of Macroeconomic Performance: Comparison of DEA-Based Alternatives, August (Public Economics).

DPS 98.30 Jïgen Janssens, Volatility and Risk Premia on Belgian Secondary Long Term Government Bond Markets, October (Financial Economics). 
DPS 98.31 Stef Proost and Kurt Van Dender, Effectiveness and Welfare Impacts of Alternative Policies to Address Atmospheric Pollution in Urban Road Transport (Public Economics).

DPS 98.32 Inge Mayeres and Stef Proost, Marginal Tax Reform, Externalities and Income Distribution (Public Economics). 